\title{
Prediction of thermal properties of ternary systems of 2,2'oxybis[propane]+ benzene, toluene, cyclohexane or $\mathrm{n}$-heptane
}

\author{
S. Didaoui, and A. Ait-Kaci
}

Laboratoire de thermodynamique et de modélisation moléculaire, Faculté de chimie, Université des Sciences et de la Technologie Houari Boumediene B.P.32, El-Alia Bab-Ezzouar 16111 Alger, Algeria

The experimental enthalpies of mixing data of three liquid ternary mixtures and their corresponding binaries of DIPE with benzene, toluene, cyclohexane and n-heptane have been measured at $303.15 \mathrm{~K}$ and constant pressure using a Calvet type microcalorimeter, C80 (Setaram, France). A Redlich-Kister type equation was used to correlate experimental values.

The theoretical results obtained by the DISQUAC and UNIFAC DO models are significantly closer to the experimental values. 